\title{
Redes de Difusión-Recepción del Conocimiento Pedagógico: La circulación del discurso educativo de John Dewey en la Lusofonía
}

\section{Diffusion-Reception Networks of Pedagogical Knowledge: The circulation of John Dewey's educational discourse in the Luso-Afro-Brazilian space}

\section{Diffusion-Réseaux de Réception du Savoir Pédagogique: La circulation du discours éducatif de John Dewey dans I'espace Luso-Afro-Brésilien}

\author{
Ana Isabel Madeira \\ Universidade de Lisboa, Portugal
}

RESUMEN

Este artículo aborda la apropiación del pensamiento de John Dewey, en el marco de estudio de las redes de comunicación y las tesis de la difusión-recepción del conocimiento educativo en el espacio luso-afro-brasileiro. Analiza el diálogo entre el movimiento portugués de la "Escola Nova," el escolanovismo brasileño y la construcción de los sistemas de educación coloniales durante las primeras décadas del Siglo XX. El texto pretende dar cuenta de los resultados de los proyectos realizados en la última década, en los que han trabajado historiadores de la educación portugueses, africanos y brasileños. El artículo propone un conjunto de ejes de desarrollo de la investigación histórico-comparada en la lusofonía, procurando contribuir a la definición/identificación del campo de las comunicaciones educativas entre Portugal, África y Brasil, en particular del lugar de John Dewey en la producción de un conocimiento educativo especializado.

Descriptores: educación comparada; historia de la educación; educación colonial; procesos de recepción-adopción; semánticas y discursos históricos. 


\begin{abstract}
This article addresses the question of the appropriation of John Dewey's pedagogical ideas in relation to the study of communication networks and the thesis of diffusion-reception of educational knowledge in the Luso-Afro-Brazilian space. It aims at the analysis of the interactions that took place between the Portuguese movement known as "Escola Nova," the Brazilian "Escolanovismo," and the construction of colonial educational systems, in the early decades of the twentieth century. It tries to assess the results of projects undertaken during the last decade by Portuguese, African, and Brazilian researchers in the field of educational history in a comparative perspective. It tries to set a development axis for comparative-history research in the Lusophone space by identifying the educational transfers between Portugal, Africa, and Brazil. It aims at clarifying John Dewey's contribution towards the establishment of specialized educational knowledge.
\end{abstract}

Key words: comparative education; history of education; colonial education; reception-adoption processes; historical semantics and discourses.

\title{
RÉSUMÉ
}

Cet article traite de la question de l'appropriation des idées pédagogiques de John Dewey en relation à l'étude des réseaux de communication et la thèse de la diffusion-réception du savoir éducatif dans l'espace luso-afro-brésilien. L'article vise à analyser les interactions qui ont eu lieu entre le mouvement portugais appelé « Escola Nova ", la " Escolanovismo » brésilienne et la construction des systèmes éducatifs coloniaux dans les premières décennies du vingtième siècle. L'auteur tente d'évaluer les résultats des projets entrepris durant la dernière décennie par la recherche comparative-historique portugaise, africaine et brésilienne dans le domaine de l'histoire éducative et dans la perspective comparative. Il vise à tracer un axe de développement pour la recherche comparative-historique dans la sphère lusophone en identifiant les transferts éducatifs entre le Portugal, l'Afrique et le Brésil. Il vise à clarifier la contribution de John Dewey à l'établissement du savoir éducatif spécialisé.

Mots clés : I'éducation comparée; I'histoire de l'éducation; l'éducation coloniale; les processus de réception/adoption; la sématique historique et les discours historiques.

\section{Introducción}

$\mathrm{E}^{\mathrm{s}}$ L PRESENTE ARTículo trata de la apropiación del pensamiento de John Dewey en el marco de estudio de las redes de comunicación y las tesis sobre la difusiónrecepción del conocimiento educativo entre Portugal, África y Brasil. Analiza, en particular, el diálogo entre el movimiento portugués de la "Escola Nova," el escolanovismo brasileño y la construcción de los sistemas de educación coloniales durante las primeras décadas del Siglo XX. Pasa revista a las investigaciones sobre el tema de la última década, que están marcadas por una intensa cooperación entre instituciones e investigadores portugueses, africanos y brasileños en el ámbito de una Historia de la educación con una perspectiva comparada. La primera referencia será, por tanto, para el desafío lanzado por António Nóvoa al respecto del espacio lusófono, sobre la existencia de un campo teóricamente cognoscible en su especificidad. ${ }^{1}$ Este punto de partida, originado en la participación de la Universidad de Lisboa en la red europea PRESTiGE, en 1998, se extendió para el universo lusófono al colaborar con instituciones de investigación e investigadores brasileños y africanos de habla portuguesa. $^{2}$ El proyecto, que había de estudiar países con diferentes sistemas económicos, 
políticos y culturales, con temporalidades propias e identidades e imaginarios particulares, presuponía emprender un trabajo de elaboración conceptual que pudiese operacionalizar una lectura renovada de las principales fuentes educativas lusófonas en términos histórico-comparados. La perspectiva aquí adoptada implica emprender un viaje a través de los referidos mecanismos de difusión y recepción del discurso educativo y de la filosofía de acción propuesta por el pedagogo americano — en Brasil, África y Portugal - intentando encontrar la especificidad teórica de esta comunicación luso-afro-brasileña. Al recapitular los resultados de la investigación comparada entre Portugal, África y Brasil, el artículo presenta algunas contribuciones a la identificación de esa "especificidad teórica," terminando con algunas propuestas de trabajo que permiten comprender algunas particularidades de las comunicaciones educativas entre países lusófonos.

\section{Referentes teórico-metodológicos}

\section{El movimiento progresista americano, el pragmatismo deweyano y los movimientos de renovación pedagógica europeos}

Durante las primeras décadas del Siglo XX, marcadas por la inestabilidad generada en torno a la Gran Guerra, la transformación de las sociedades agrarias en naciones industrializadas - con el consiguiente aumento de la competencia económica, los procesos de urbanización y la creciente diversidad étnica de las sociedades occidentales - surgieron una serie de movimientos de reforma social y cultural. En la educación, varias naciones intentaron reorganizar sus sistemas educativos para responder a los procesos de cambio apelando a las nuevas maneras de gobernar el desarrollo de las comunidades y sociedades. La creencia generalizada en la escolarización como factor de progreso, de desarrollo económico, de estabilidad política y de integración social contribuyó un conjunto de movimientos políticos y sociales centrados en una reflexión sobre la educación y orientados a la reforma de los sistemas de enseñanza. En los USA, la retórica de la "revolución educacional," período que abarca las últimas décadas del Siglo XIX y las primeras del Siglo XX, generó un clima de confianza en las virtualidades igualitarias de la educación y de optimismo en la capacidad transformadora de la escuela, a la que se consideró como una institución social de progreso y desarrollo individual y colectivo. ${ }^{3}$ En el ámbito pedagógico esta racionalidad se tradujo en un conjunto de discursos sobre el self-government que asignaron a la escuela la tarea de transformar a niños y jóvenes en ciudadanos libres, autónomos y responsables. En el marco de este movimiento se dieron un conjunto de debates centrados en torno a los fines, medios y métodos educativos que debían ser utilizados para la construcción de la sociedad democrática, incluyendo, entre otras cuestiones, aspectos ligados al currículo, la organización administrativa, la innovación en los métodos de enseñanza y la formación de los profesores.

Los proponentes del movimiento progresista americano, entre los que destacaban William James, John Dewey, William Heard Kilpatrick, Harold Rugg y Ann Shumaker, consideraban que, para responder a los desafíos de la educación en los 
USA, sería preciso revolucionar completamente los procesos de enseñanza utilizados en las escuelas. Frente a un tipo de enseñanza tradicional, centrado en la autoridad del maestro, un currículo abstracto desligado de las realidades cotidianas y una concepción del alumno como elemento pasivo y sumiso, propugnan una reforma centrada en la transformación radical de los métodos de trabajo en la clase, hasta entonces centrados en la figura del profesor y en los contenidos "simbólicos" de las materias escolares. La educación progresista fue un movimiento de reforma de la educación que, según el propio Dewey, se originó en el trabajo de Francis W. Parker, en Massachusetts, en $1870 .^{4}$

El término fue vulgarizado a partir de los años 80 del Siglo XIX para referirse, unas veces, a la formación vocacional industrial y artesanal y, otras, para designar técnicas pedagógicas innovadoras, a semejanza de las que Parker había desarrollado en la escuela de Quincy. Pero fue Dewey quien incorporó y confirió unidad a esta última preocupación, sometiendo al progresivismo a la criba del experimentalismo pedagógico y subrayando, en un conjunto de obras, la importancia capital de la epistemología científica en el conocimiento y los métodos de enseñanza centrados en el niño. Este énfasis era esencial para ponderar la construcción de la sociedad democrática y para pensar la formación de ciudadanos útiles e independientes. La denuncia de Dewey de la enseñanza de raíz "medieval" y la defensa de otra escuela, proclamada ya en La Escuela y la Sociedad, (2002 [1900]) fueron dos aspectos que unieron a los movimientos de renovación pedagógica en los inicios del Siglo XX a ambos lados del Atlántico.

En el marco de esa "evolución social más vasta," el movimiento progresista americano acompañó los movimientos de renovación pedagógica europeos - tanto en su fundamentación filosófica (Montaigne, Rousseau, Herbart, Spencer) como práctica (Pestalozzi, Froebel) — diseñando un lenguaje común en torno a la Educación Nueva y la Escuela Activa. En Europa, los autores de referencia del ideario filosófico-pedagógico de la Escuela Nueva - Desmoulins, en Francia; Decroly, en Bélgica; Ferrière y Claparède, en Suiza, Montessori, en Italia; Adolfo Lima, en Portugal — propugnan, en términos muy semejantes a los del lenguaje americano, un nuevo papel para la escuela, dirigida a la construcción de un nuevo ciudadano autónomo, responsable y libre. El diálogo entre la Escuela Nueva y el movimiento progresista conoció una nueva fase con la divulgación, a escala global, del pragmatismo de Dewey. Durante los años en que dirige la "escuela experimental" en la Universidad de Chicago (1894-1904), Dewey construirá una teoría del conocimiento basada en el pragmatismo y el naturalismo. Al observar a sus alumnos, Dewey se convenció de que, al ser confrontados con actividades susceptibles de movilizar sus intereses y necesidades, los niños eran capaces de aprender y resolver problemas con éxito. Antes de entrar en la escuela, el niño ya era un ser intensamente activo y la educación debería consistir, precisamente, en aprovechar y dirigir esa capacidad creativa del niño. Los niños llevaban consigo intereses y actividades relacionadas con su medio ambiente, cabiéndole a la escuela y al maestro potenciar esos intereses con la vista puesta en su desarrollo. De cierta forma, pues, Dewey defendía una pedagogía funcionalista centrada en la construcción de relaciones entre el trabajo intelectual y las necesidades prácticas, a 
través de tareas destinadas a despertar los intereses y capacidades de los niños. La adquisición de conocimientos se tornaba, de esta forma, un instrumento de resolución de problemas relacionados con la experiencia vivida y con los conocimientos y saberes acumulados en el día a día. La mejor forma de relacionar los aprendizajes escolares con las actividades cotidianas consistía, precisamente, en la aplicación de métodos activos, en aprender haciendo-learning-by-doing—-método a través del cual los contenidos educativos reproducían efectivamente las "condiciones de la vida real." ${ }^{5} \mathrm{Al}$ atribuir al método científico una capacidad instrumental para el planeamiento social, el pragmatismo se transformó rápidamente en una herramienta metodológica adecuada a la resolución de prácticamente todos los problemas educativos, asumiendo un papel cada vez más prominente en los discursos científicos y políticos de reforma educativa. ${ }^{6}$

\section{La internacionalización de la razón educativa}

\section{El pragmatismo de Dewey y la construcción de los sistemas de educación coloniales en los inicios de Siglo XX}

Las ideas de Dewey se internacionalizaron a través de innúmeras vías: por la publicación de artículos en revistas pedagógicas europeas ${ }^{7}$ y americanas $;{ }^{8}$ traducciones de sus obras y también, por medio de la participación de Dewey en conferencias y congresos pedagógicos internacionales. No hay duda de que las ideas filosóficas y pedagógicas de Dewey viajaron por diversos países de los cinco continentes acompanándole en sus visitas o conferencias: Japón (1919), China (1919-1921), Turquía (1924), México (1926), U.R.S.S. (1928) y África de Sul (1934).?

En cuanto a la apropiación diferenciada del pensamiento de Dewey a través de naciones con tradiciones históricas e intelectuales tan dispares, Thomas Popkewitz se pregunta por la matriz que torna al pragmatismo de Dewey en un sistema de principios accesible a proyectos de reforma radicalmente diferentes en todo el mundo. Una de las nociones que propone para analizar el conjunto de circuitos y redes que se trazan con los viajes del pragmatismo por todo el mundo es, justamente, el concepto de bibliotecas itinerantes - traveling libraries — noción que intenta poner al descubierto las diferentes amalgamas de proyectos pedagógicos y posiciones ideológicas que se combinaron para conferir inteligibilidad a los procesos de cambio. ${ }^{10}$

En un análisis de la apropiación de los discursos del pedagogo norteamericano para la educación en África ${ }^{11}$ se constató que la diversidad de estrategias y posicionamientos ideológicos a las que el pragmatismo de Dewey fue sometido fue extremadamente compleja. A semejanza de lo que sucediera en otras regiones del mundo, los principios del progresivismo y pragmatismo transitaron por África a través de la acción de determinados grupos sociales, religiosos y políticos, sin que su autoría fuese explícitamente referida. Estos principios fueron desmontados e incorporados a los distintos discursos pedagógicos y políticos de acuerdo con las intenciones y las estrategias particulares de cada gobierno colonial, acabando por configurar discursos híbridos sobre la escuela y la formación (en particular dirigidos a la educación de 
los niños indígenas en el medio rural) en torno a nociones tales como "adaptación," "conformidad," "métodos activos," "medio envolvente," "educación por el trabajo," "escuela-comunidad," "trabajo manual," etc. ${ }^{12}$

Dewey emergía en estos discursos como una conceptual personae, como soporte pedagógico-científico de un conjunto de intereses, estrategias y dispositivos locales destinados a la incorporación educativa de los africanos en un sistema de enseñanza pensado a medida de "sus necesidades." Algunas nociones tales como la de "aprender haciendo" - learning by doing - fueron antes desligadas de su contexto original (y de su aplicación en tanto método activo de aprendizaje), para religarlas a argumentos que tenían muchas veces finalidades contrarias a los principios del pragmatismo. Estos argumentos incluían, por ejemplo, la defensa de un tipo de enseñanza diferente para blancos y africanos que se basaba en la diferencia de capacidades entre ambos; la defensa de la enseñanza vocacional como un tipo de enseñanza especialmente ajustado a las necesidades de los africanos (legitimando así las barreras académicas impuestas a estos) o sirvieron para justificar tipos de currículos esencialmente orientados a la práctica, basados en las necesidades "culturales" de la comunidad (identificadas de partida con el trabajo en la tierra, la industria o los oficios).

Por otro lado, en las colonias (en particular en las zonas rurales) el "africano" ocupó el lugar que Dewey destinara al "niño." El discurso sobre la educación del "negro" se construyó casi siempre a partir de una concepción infantilizada del africano, individuo que era necesario proteger (de la barbarie) y acoger (en la dominante civilización occidental). En tanto objeto infantilizado, subyugado y subalterno, la enseñanza destinada al africano daba por supuesto, el ajuste de la educación a su condición inferior. Fue esta, precisamente, una de las razones que legitimó la utilización continuada de metodologías de enseñanza por y para el trabajo, basadas en la apología de la 'educación vocacional', para ligar al negro al trabajo manual, siguiendo argumentos de progreso colectivo (del cual los africanos se encontraban claramente apartados por su condición social). Estas nociones, que fueron difundidas a través de la acción de las sociedades misioneras protestantes, inglesas y americanas, pasarán, paulatinamente, a integrar el discurso educativo del Colonial Office británico. Por "efecto de redundancia," transitarán a los discursos de las administraciones coloniales portuguesa y francesa, que efectuaron, a su vez, las correspondientes apropiaciones específicas. En el proceso de construcción del modelo de la "educación adaptada" se reconstruyeron las ideas Dewey a imagen de las necesidades políticas y de las ideologías locales, promoviendo algunos de sus presupuestos y eliminando u omitiendo otros (la participación democrática, el interés de los niños, el desarrollo de la comunidad, la participación en progreso científico y económico, etc.). En realidad, la presencia de Dewey en África fue ajena a la consagración del modelo de la "educación adaptada" (en las colonias inglesas) o de la "enseñanza de adaptación" (en las portuguesas). Así, Dewey funcionó como, para utilizar la metáfora de Thomas Popkewitz, un indigenous foreigner, un "autor" a partir del cual los discursos de los reformistas coloniales reconstruyeron nociones e ideas foráneas como si fuesen "naturalmente" autóctonas, con el objetivo de legitimar el cambio y la construcción de tipos de alumno, profesor, currículo y enseñanza adecuados al escenario colonial. ${ }^{13}$ 


\section{Las redes y los circuitos de circulación de los modelos pedagógicos en África}

La participación de Dewey en la conferencia "Educational Adaptations in a Changing Society," organizada por la New Education Fellowship (NEF) en África del Sur en julio de 1934 fue, por lo que sabemos, la única visita de Dewey a un país del África Subsahariana. ${ }^{14}$ En sí mismo, este hecho no es muy significativo dado que el trabajo de Dewey era ya muy conocido en los círculos ligados a la educación colonial de diversos imperios europeos. Esa visita a África representó, en un momento en que Dewey estaba a punto de cumplir 75 años, sobre todo, el reconocimiento de la importancia de los métodos americanos de enseñanza y del pragmatismo como un conjunto de conceptos, métodos y técnicas relevantes para la reforma educativa, bien para el gobierno, bien para las misiones protestantes. ${ }^{15}$

Los métodos americanos de enseñanza ya eran conocidos por los europeos por medio de Omer Buyse. ${ }^{16}$ Por otro lado, el pragmatismo alcanzará notoriedad internacional a través de la investigación desarrollada en Teachers College de la Universidad de Columbia, en Nueva York, institución que formará muchos profesores para las universidades africanas. Con todo, las redes y los circuitos de difusión del progresivismo y pragmatismo de Dewey en África, se formaron a través de intrincados nexos entre grupos, organismos y asociaciones que asumieron una parte activa en la construcción de los sistemas educativos africanos. Para analizar esta red es preciso tener en cuenta el conjunto de relaciones que ligaron, en los tres continentes (Europa, Estados Unidos de América y África), a un grupo muy diverso de agentes entre los que se contaban las fundaciones filantrópicas, los grupos políticos y religiosos, las universidades e institutos pedagógicos y los gobiernos y administraciones locales.

El primero de estos ejes se estableció a finales del Siglo XIX, con la relación entre las sociedades misioneras protestantes norteamericanas y el Phelps-Stokes Fund. El segundo envolvió a las sociedades misioneras protestantes inglesas y el Colonial Office británico, incluyendo la acción del Advisory Committee on Education in the Colonies, sobre todo en las primeras décadas del Siglo XX. El tercer eje articuló las relaciones que envolvieron al Teachers College de la Universidad de Columbia, en Nueva York, el Instituto Jean Jacques Rousseau, en Ginebra y el Institute of Education, en Londres, a fines de los 20 y principios de los 30 . El cuarto eje envolvió el diálogo trabado en las revistas científicas y divulgado en los congresos internacionales, en particular la revista Oversea Education (en Inglaterra) y la acción de New Education Fellowship en el plano de las conferencias regionales organizadas en el marco de la Commonwealth (con prolongaciones en las revistas The New Era y Pour l'Ėre Nouvelle). Finalmente, un último eje se conformó a través de la circulación de un conjunto de informes, opiniones, trabajos de investigación y normas legales que circularon entre las diversas colonias británicas, vulgarizando el uso de determinadas expresiones, conceptos e ideas ligadas al pragmatismo de Dewey sin citarlo directa o indirectamente. ${ }^{17}$ La sobreposición de estos ejes de relaciones en los diálogos que se fueron estableciendo a través de su infiltración en la administración colonial local contribuyó a diseñar una red muy compleja de interacciones y referencias, evidenciando 
que las cuestiones relacionadas con los procesos de transferencia de ideas, conceptos y teorías educativas configuran un área de trabajo que va más allá del análisis de los procesos de difusión-recepción (o de apropiación-tergiversación) y la investigación de su posible origen primario. Considerando algunos ejemplos:

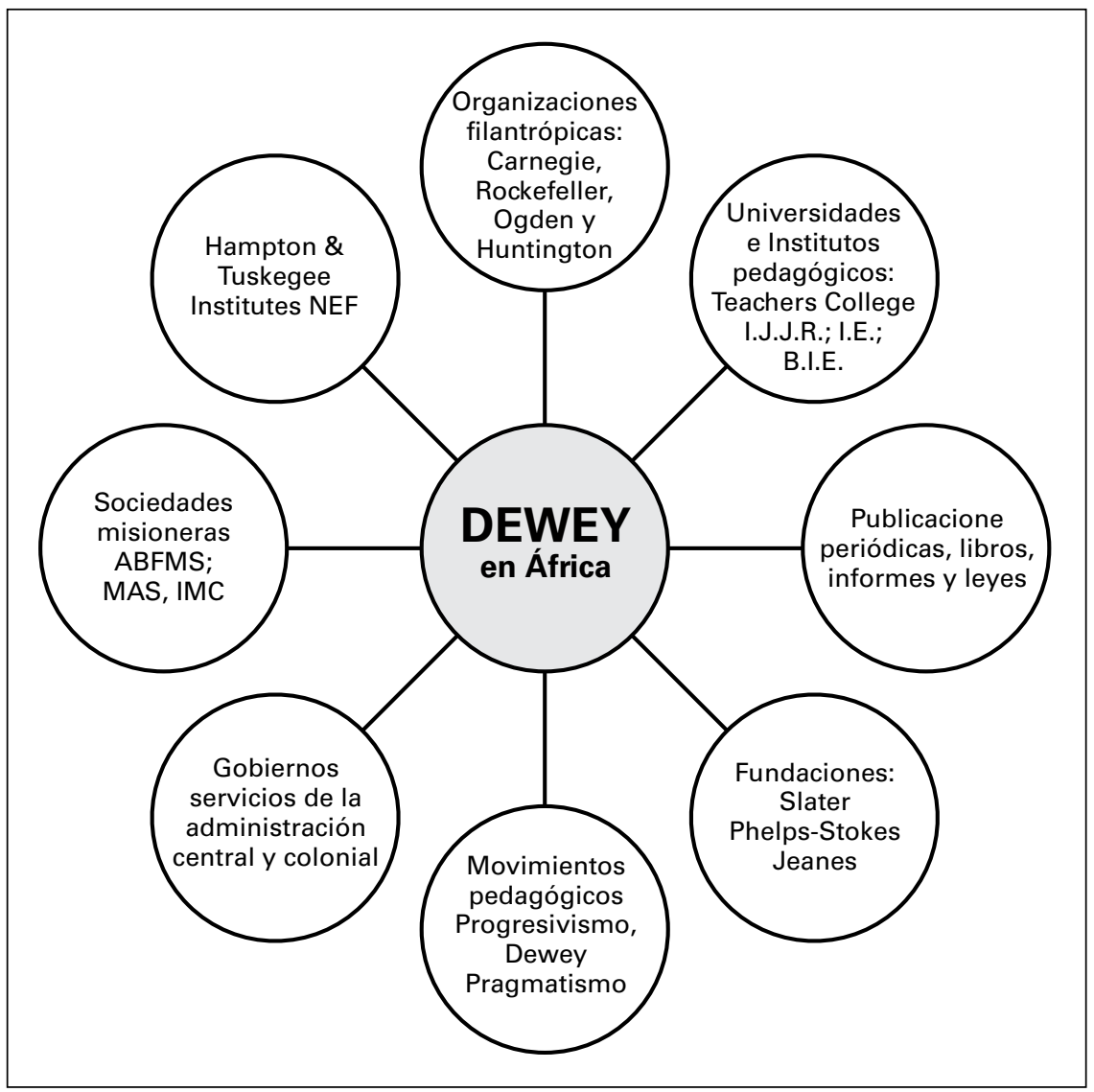

Figura 1: Redes y circuitos de difusión de los discursos educativos

Isaac Kandel consideraba que la popularidad mundial del pragmatismo residía en que ofrecía una respuesta a la insatisfacción generalizada frente a los conceptos liberales de la cultura y la educación. ${ }^{18}$ Esta insatisfacción generalizada encontraba en la racionalidad (y la operatividad) del pragmatismo un conjunto de ideas y nociones sobre la constitución del niño como agente de cambio, al mismo tiempo que parecía asegurar una base científica para la resolución de problemas a través de la reorganización de la vida cotidiana y de las comunidades. Entre tanto, el movimiento de la educación progresiva significaba cosas muy diferentes para individuos y grupos distintos en la propia sociedad norteamericana, lo que originó fuertes debates. ${ }^{19}$ La utilización de la escuela como vehículo de desarrollo social comprendía por lo menos tres aspectos. En primer lugar, 
tenía como objetivo la extensión del currículo y de las funciones de la escuela para incluir la salud, la enseñanza vocacional, la calidad de la vida familiar y comunitaria. En segundo lugar, el progresivismo en la educación significaba adaptar la instrucción a clases y tipos de niños cada vez mas diversificados, razón por la cual no sólo los métodos sino también los programas tenían que ser alterados. Por último, el progresivismo implicaba una creencia generalizada en la participación de todos en la construcción de una nueva cultura, donde cada ciudadano podría disfrutar de los beneficios alcanzados por las nuevas ciencias, así como del progreso económico y tecnológico en general. Segundo, un nombre aparentemente genérico, "revolución progresista," pretendía responder a diversos "problemas" de la enseñanza y se refería a "diversos tipos" de escuela: la expresión podía implicar el objetivo de transformar la escuela en un centro comunitario, siguiendo una ideología próxima de la "educación social"; podía referirse, pura y simplemente, a la "educación vocacional"; o bien, podía también representar un tipo de educación orientado al "trabajo en la agricultura." Sobre esta multiplicidad de sentidos subsistía una idea central —el ajuste de la escuela a la sociedad - idea transversal a los varios discursos sobre la reforma educativa en los USA de los inicios del Siglo XX.

\section{Las apropiaciones de discurso: Dewey en el contexto colonial}

Una de las ideas centrales del movimiento progresivo americano sustentaba que, para responder a los cambios económicos, sociales y culturales de occidente, la escuela habría de ajustarse a la sociedad. Ese ajuste se pensaba en el marco de una reforma global del sistema de enseñanza (del currículo, la formación de los profesores, de los métodos pedagógicos) implicando igualmente una revolución en las relaciones entre la escuela, la familia y la sociedad en su conjunto. Dewey consideraba que la escuela debía cultivar en los alumnos una sensibilidad social y cooperativa y desarrollar en ellos el espíritu democrático. El objetivo de la escuela era formar ciudadanos libres, responsables, capaces de autogovernarse - un conjunto de conceptos que se inscribían en el ideario de la Escuela Nueva y en el que Dewey participaba. La escuela de Dewey era, sobre todo, una comunidad democrática y, como tal, una experiencia de educación para la democracia. En este sentido, la escuela no era concebida como un simple instrumento de reproducción social. Evidentemente, el filósofo-pedagogo pretendía ligar la escuela a la vida social exterior colocando las actividades productivas - las ocupaciones — en el centro de su programa; mientras que situaba las relaciones sociales de producción en un contexto cooperativo, libre de cualquier constreñimiento material. La finalidad de Dewey no era promover la sociedad capitalista, sino desarrollar las capacidades que permitiesen a los ciudadanos poder hacer uso de sus beneficios. En este proceso, la educación y la escuela desempeñaban un papel crucial para la emancipación individual $y$, consecuentemente, de la sociedad.

La concepción de un sistema de enseñanza ajustado al contexto colonial era una idea que venía siendo elaborada desde finales del Siglo XIX por los Institutos Tuskegge y Hampton en los estados de Virginia y Alabama. Con la formación de redes internacionales de circulación de conocimientos pedagógicos, la transversalidad de la cuestión del ajuste de la escuela a la sociedad encontró en el contexto colonial un 
terreno de experimentación para el desarrollo de discursos reformistas. Los principios del progresivismo americano relacionaban un conjunto de preocupaciones comunes tanto a los gobiernos occidentales como a los diversos agentes locales - gobernadores, misioneros, profesores - en concreto, la cuestión del cambio social, la enseñanza profesional y el valor de la "educación social.” Además, la pedagogía democrática del pragmatismo mantenía con el cristianismo protestante numerosos puntos de contacto. Cuando afirmaba que la escuela representaba una sociedad en estado embrionario, Dewey proponía un proyecto radical de sociedad, a partir de la reforma de la escuela y este propósito mantenía muchas semejanzas con el discurso de las congregaciones protestantes sobre la creación de una sociedad democrática.

Los misioneros protestantes consideraban la congregación como el núcleo esencial de la iglesia y estaban muy empeñados en su organización democrática, fomentando la participación y la cooperación de cada individuo para el progreso colectivo. Este objetivo tenía, evidentemente, un contrapunto en la idea de la "creación de la comunidad africana," una concepción omnipresente en la doctrina política de los gobiernos coloniales británicos que se prolongaba a la acción de las misiones protestantes (americanas e inglesas) instaladas también en otros territorios coloniales (sobre todo en Mozambique). Como regla general, las misiones protestantes se preocupaban de la práctica religiosa social y poco de especulaciones teológicas, organizando sus actividades en torno a particularismos locales (la lengua, la cultura, el medio ambiente). Una vez que la acción de las misiones protestantes no se centraba en el dogma teológico, sino en una moral social de inspiración religiosa, la secularización del currículo no se presentaba como una dificultad para los protestantes, ya que, para los misioneros, la ciencia y la religión no eran incompatibles.

Tal como tampoco lo eran para Dewey. El pedagogo creía que la reforma social a través de la escuela democrática tenía que trabajar en la unificación de los "lenguajes" del mundo ideal y de la realidad, con la vista puesta en una finalidad común. En una carta de 1892 a Joseph Denney, rector del College of Arts, Philosophy, and Science de la Universidad de Ohio, Dewey afirmaba: "The 'unified language' seems to be the most complete expression of what the 'idea' does in thought, how religion has one language, philosophy another, science another, literature another, and so on. Seeing the common objective fact, we get the unified language - the language of action. This is democracy - the appropriation of the store of spiritual wealth in all directions by the whole and common people." ${ }^{20}$ Era esta riqueza espiritual la que se vertía en un evangelio social secular encarnado en la "creencia" en el potencial de la educación y la "fe" en los métodos pedagógicos. Así, en un escenario en el que la misión y la escuela se presuponían mutuamente, no era difícil pensar que el pragmatismo conferiría a la doctrina cristiana una legitimidad científica. El Cristianismo y el pragmatismo compartían, a este respecto, principios que se reforzaban mutuamente. La siguiente tabla pretende dar una panorámica de las reconfiguraciones discursivas que transformaron los principios filosófico-científicos del pragmatismo en una doctrina pedagógica transversal a varias colonias africanas en los inicios del Siglo XX. Esta tabla intenta resumir las apropiaciones selectivas, en particular, las transformaciones restrictivas a que estas dieron lugar, en el contexto colonial. ${ }^{21}$ 


\begin{tabular}{|c|c|c|}
\hline USA $\leftrightarrow$ Europa & & $\begin{array}{c}\text { África } \\
\text { (Colonias británicas } \leftrightarrow \text { colonias } \\
\text { portuguesas) }\end{array}$ \\
\hline $\begin{array}{l}\text { Ajuste de la escuela a la sociedad } \\
\text { (Escuela/medio social) }\end{array}$ & \multirow{10}{*}{ John Dewey } & $\begin{array}{l}\text { Educación adaptada } \\
\text { (escuela/medio rural) }\end{array}$ \\
\hline Progresivismo/Pragmatismo & & Pietismo/Evangelio social \\
\hline $\begin{array}{c}\text { Democracia/Modernización/ } \\
\text { Progreso } \\
\text { (Educación como valor social) }\end{array}$ & & $\begin{array}{l}\text { Civilización/Progreso económico } \\
\text { y social } \\
\text { (Educación como valor moral y } \\
\text { económico) }\end{array}$ \\
\hline $\begin{array}{c}\text { escuela como microcosmos social } \\
\text { (Cualidad /experimentación/ } \\
\text { innovación) }\end{array}$ & & $\begin{array}{l}\text { escuela como un laboratorio social } \\
\text { (Cantidad/medida/evaluación) }\end{array}$ \\
\hline Ciudadanos libres & & Ciudadanos civilizados \\
\hline $\begin{array}{c}\text { Escuela Activa } \\
\text { (aprendizajes centrados en la } \\
\text { experiencia) }\end{array}$ & & $\begin{array}{l}\text { Currículo Activo } \\
\text { (aprendizajes centrados en } \\
\text { "aprender haciendo") }\end{array}$ \\
\hline $\begin{array}{c}\text { Formación vocacional } \\
\text { (Formación de mano de obra } \\
\text { cualificada) }\end{array}$ & & $\begin{array}{l}\text { Orientación vocacional } \\
\text { (adquisición de hábitos de trabajo) }\end{array}$ \\
\hline $\begin{array}{l}\text { Industria, agricultura, servicios y } \\
\text { comercio }\end{array}$ & & $\begin{array}{l}\text { Agricultura, artes y oficios, } \\
\text { "ciencias domésticas" }\end{array}$ \\
\hline $\begin{array}{l}\text { El “niño” en el centro de la } \\
\text { educación (construcción de } \\
\text { individuo/necesidades de los } \\
\text { niños/sacralización del niño/ } \\
\text { autogobierno) }\end{array}$ & & $\begin{array}{l}\text { La "comunidad" en el centro } \\
\text { de la educación } \\
\text { (disciplina /ortopedia social/ } \\
\text { salvación por el trabajo) }\end{array}$ \\
\hline "Gubernamentalidad" & & "Gobierno a distancia" \\
\hline
\end{tabular}

Tabla 1: El Pragmatismo de Dewey y sus apropiaciones selectivas en el contexto africano

Para la lectura de esta tabla esbozaremos, a continuación, un guión. La articulación del evangelio progresista americano (la revolución educativa, la democracia, el progreso), con la ética de la misión protestante en África (la noción de esfuerzo, sacrificio, autonomía, auto-subsistencia) y su apertura permanente al discurso científicopedagógico del pragmatismo (el "self-government," la escuela activa, la ciudadanía) solo se volvió posible porque estos movimientos compartían entre sí múltiples principios y finalidades. Fue, sin duda, en el marco de esta comunión de intereses que los discursos sobre la educación adaptada pudieron edificar un código de referencia común. Con todo, su apropiación en el contexto colonial y la traducción de esta semántica educativa en políticas y prácticas educativas operó una transformación e, incluso, una reversión de sus presupuestos filosófico-morales y objetivos originarios. De hecho, la principal preocupación del gobierno colonial británico era controlar y dirigir el cambio social (la destribalización, la urbanización acelerada, los conflictos 
raciales). Este objetivo no era, de ninguna manera, aquel perseguido en los USA y en Europa, donde pretendía imprimir una racionalidad cosmopolita a la educación del ciudadano a través de la escuela. En las colonias, la movilización del ideario del progresivismo americano y, posteriormente, del pragmatismo resultó en una apropiación selectiva, de sentido restrictivo, principalmente porque aquellas poblaciones no se encontraban todavía, según los estándares occidentales, en condiciones de participar en un cosmopolitismo "civilizado." La insistencia en la representación de las sociedades africanas como un "grupo étnico" atrasado y, paradójicamente, la referencia constante al peligro de la mentalidad indígena, requerían un tipo de intervención ajustado a su condición "arrièreé." 22

En cuanto a las cuestiones pedagógicas propiamente dichas, el movimiento progresivo propugnaba un currículo centrado en los intereses de los niños, al considerar a estos como el centro neurálgico del cambio de paradigma de enseñanza. El pragmatismo de Dewey admitía este cambio colocando el acento en el proceso de enseñanza, modificando la relación profesor-alumno y proponiendo una organización curricular centrada en los intereses de los niños a través de la dinamización por los aprendizajes activos. Como Dewey consideraba que la educación poseía un valor esencialmente social, los currículos deberían ser construidos teniendo en cuenta las distintas etapas de desarrollo de los individuos y relacionar sus contenidos con el medio ambiente. Su principal objetivo era la sustitución de los currículos formales, abstractos y teóricos por procesos de aprendizaje en los que las materias fuesen insertadas en la experiencia de los alumnos. Era ese el sentido, en Dewey, de la metodología del "learning by doing." Por otro lado, el papel del profesor en la dinamización del aprendizaje por la experiencia presuponía una conexión constante de las materias enseñadas con los contextos vitales de los niños y de la comunidad. Por el contrario, en el contexto colonial, el lugar del niño va a ser ocupado por lo colectivo, por la "comunidad," considerada como una entidad con iguales capacidades, necesidades y destino. En nombre de la estabilidad y de la armonía se asignaban a este colectivo características que debían ser corregidas (alcoholismo, poligamia, brujería), cualidades laborales que debían ser disciplinadas y necesidades materiales y espirituales que debían ser creadas. Por esa razón, la asociación entre el evangelio y la moral social eran instrumentales para asegurar el dominio de la racionalidad colonizadora. Cualquiera de estas transformaciones implicaba una visión infantilizada del africano, incapaz de conducirse a sí mismo hacia la civilización, legitimando, al mismo tiempo, la tarea de conducir al indígena al "self-government" y la de ejercer, en su nombre, el mejor gobierno.

El sentido restrictivo de esta apropiación se reflejó en el tipo de oferta educativa que los gobiernos coloniales diseñaron con miras a la aproximación del africano a su propia comunidad. En efecto, la cuestión de la profundización de la relación de la escuela con la comunidad no fue encarada según la perspectiva que Dewey le había atribuido, esto es, como una forma de realizar la democracia a partir de la escuela, de ejercer la participación y de promover las potencialidades del individuo buscando su emancipación como ciudadano. No se trató, de hecho, de poner en práctica los principios del pragmatismo, sino de instaurar una racionalidad pragmática destinada a garantizar una educación de segunda, discriminatoria y subalterna, totalmente 
contraria a los ideales democráticos de Dewey. ${ }^{23}$ La valorización de los currículos activos, la importancia atribuida a los métodos de "learning by doing," la apuesta por una enseñanza vocacional ligada a la agricultura y a los oficios - aspectos transversales a la tesis de la "educación adaptada" — solo tomaron del pragmatismo de Dewey un nuevo reconocimiento, haciendo creer que la política educativa colonial participaba de las modernas teorías científicas. En realidad, la apropiación del pragmatismo, supuso no la implementación de una política emancipadora sino que, antes bien, trató de "aherrojar" a los africanos a determinadas ocupaciones evitando que se creasen expectativas relativas a la progresión académica. El énfasis atribuido a la enseñanza vocacional se restringió a un entendimiento de política educativa orientada a la educación para y por el trabajo; la relación escuela-comunidad fue defendida para reforzar las relaciones tradicionales comunitarias procurando impedir las migraciones y la destribalización; el evangelio social incidía más en las cuestiones morales que en las sociales. En este sentido, la defensa de currículos activos fue sobretodo entendida como un medio de promover la adecuación de los africanos a determinados sectores de actividad económica, principalmente a la agricultura, en cuanto que las metodologías de aprender haciendo se destinaban, esencialmente, a hacer comprender el lugar del africano en el contexto de la economía colonial. La apuesta por el método Jeanes de formación de maestros confirmaba esta intención, al equiparar al profesor a un técnico de acción social, más preocupada con la instrucción vocacional de que con la "educación" en el sentido integral de término.

Diría, entonces, que Dewey no fue introducido en el discurso colonial en cuanto Dewey. Fue antes a través de las ideas, conceptos y discursos que fueron tomados, selectivamente, en préstamo al pragmatismo, que su conceptual personae legitimó una perspectiva funcional de la educación. Los discursos reformistas coloniales se alejaron, por eso mismo, de los ideales de la escuela democrática, inscribiendo un conjunto de desigualdades que se ahondaron hasta el presente, en particular la limitación de la enseñanza femenina a las ciencias domésticas o en la apología de un tipo de enseñanza rudimentaria y práctica, destinada a las tareas de ejecución.

\section{La recepción del programa deweyano en Brasil y Portugal, 1920-1950/60}

Los resultados de las investigaciones emprendidas por investigadores de ambos lados del Atlántico confirman la transversalidad de la idea del "ajuste" de la escuela a la sociedad, tanto en el África como en la América Latina de lengua portuguesa. En el marco de un análisis histórico-comparado de publicaciones en educación, el estudio de Carvalho y Cordeiro ${ }^{24}$ exploraba la circulación internacional de modelos educativos a través del análisis de la presencia y ausencia de transferencias entre Brasil y Portugal en la construcción de un conocimiento pedagógico especializado. Tomando como fuentes dos revistas pedagógicas, una brasileña (la revista Educação, de S. Paulo) y otra portuguesa (la Revista Escolar), los autores concluyeron la presencia ínfima de referentes portugueses en las páginas de la publicación brasileña. Mientras que del lado portugués se daba solo una muy discreta presencia de referencias a autores, 
movimientos pedagógicos o investigaciones sobre la escuela y la educación realizadas en Brasil. A modo de balance, los autores consideraban que, basándose en las dos revistas, difícilmente se podría afirmar la existencia de transferencias de modelos educativos entre los dos países, pero alertaban de la necesidad de efectuar un análisis complementario de otras fuentes primarias y secundarias que incluyese informes oficiales, otras revistas, legislación, manuales, correspondencia, materiales biográficos y autobiográficos. ${ }^{25}$

Éste fue desarrollado por el equipo constituido por Correia y Silva ${ }^{26}$ y Correia y Gallego ${ }^{27}$ con la misma aproximación teórica e histórico-comparada en el análisis de los manuales dirigidos a los normalistas en Brasil y Portugal. Al identificar el universo de referencias de los manuales pedagógicos, así como las articulaciones de los manuales con los programas oficialmente definidos para los cursos de formación de maestros entre 1930 y 1970 , los autores concluyeron en la existencia de elementos de continuidad, movimientos de saberes, convergencias y re-significaciones de las ideas, conocimientos pedagógicos y prácticas de enseñanza vehiculadas en los textos de los manuales. Sin duda, la fórmula cuantitativa de recogida de las referencias a autores, obras, países e instituciones no les permitió conocer el modo en que esos conocimientos pedagógicos fueron apropiados y traducidos en actos pedagógicos. ${ }^{28}$ Pero el estudio puso en evidencia las ventajas de la investigación comparada, iluminando la cuestión de la incorporación local de discursos difundidos mundialmente acerca de enseñanza, de la escuela y de la educación en perspectiva histórica. ${ }^{29}$ Por otro lado, el trabajo también aclaró el modo en el que la circulación de conocimientos pedagógicos fue construyendo las formas de auto-referencia de las sociedades lusófonas - incorporando las tesis del "atraso educacional" portugués y brasileño en el discurso educativo - al mismo tiempo que apuntaba a las sociedades y las teorías pedagógicas de referencia consideradas "modernas." El estudio concluía en que, "el análisis de las más de treinta mil referencias constantes en los libros de los normalistas evidenció qué modalidades de clasificación se realizaron de los diferentes espacios nacionales: la primera, relativa a los lugares donde se reconoció el nacimiento y desarrollo inicial del modelo escolar, la Europa Occidental; la segunda, referente a otro importante espacio de expansión de la escolarización, América del Norte y, sobretodo, los Estados Unidos; y por fin, el grupo de naciones que, según los manuales, no alcanzaron los beneficios de enseñanza, quedando al margen del centro del "discurso moderno." ${ }^{30} \mathrm{El}$ marco sugerido por ambos estudios parece indicar que la externalización a la situaciones mundiales, ${ }^{31}$ y en concreto la idealización de la sociedad norte-americana como símbolo de modernidad educativa y cuna de la escuela democrática permitió al Brasil romper con la cultura tradicional brasileña, heredada del Siglo XIX (marcada por una fuerte influencia francesa) y, al mismo tiempo, recrear una identidad y una historia al margen de los orígenes portugueses.

En Portugal la referencia a ejemplos del extranjero, una externalización capaz de sustentar reformas congruentes con el ideario de la I República (1910-1926), dio señales de que la movilización selectiva de modelos educativos se situaba preferencialmente en el universo francófono (francés, belga y suizo) y en Alemania. En la primera lectura, todo indica que ni en Portugal ni en Brasil surgieron modelos que el otro país 
quisiera imitar ni, siquiera, contrariar. ${ }^{32}$ Todavía, el primer grupo de investigadores, ${ }^{33}$ que tomaron por objeto la comparación estricta entre la presencia de referentes extranjeros en el discurso de las comunidades disciplinares de la educación en dos de los países de la lusofonía; mientras el segundo, ${ }^{34}$ llevando la comparación al terreno de los mecanismos de apropiación en el espacio luso-brasileño según la perspectiva de Chartier (1990) contribuyeron a identificar un conjunto de aspectos cruciales para comprender los mecanismos de difusión-recepción del conocimiento educativo en el espacio lusófono. La utilización amplia de marcos de referencia comunes (autores, obras, países, periódicos, organizaciones, modelos pedagógicos) aunque externos a cada una de las naciones, permite tomar como hipótesis de trabajo la existencia de un campo de comunicaciones ibero-americanas, de múltiples redes de comunicación y de circulación de saberes pedagógicos entre Portugal y Brasil, bien por vía de Europa, incluyendo una posible intermediación de España, o de América de Norte.

Es un hecho que las investigaciones sobre la recepción del pragmatismo de Dewey en Brasil se encuentran mucho más avanzadas que el correspondiente análisis en Portugal ${ }^{35}$ Este conjunto de obras documenta ampliamente la recepción, apropiación y la "recontextualización" del pensamiento de Dewey en Brasil a través de las obras traducidas, de los artículos científicos publicados, de los manuales de enseñanza o del mismo discurso político y legislativo. En Portugal, a pesar de que el movimiento progresista americano acompañó a los movimientos europeos de renovación pedagógica, las redes entre el movimiento progresista, el pragmatismo deweyano y la Escola Nova portuguesa no han sido consideradas como objeto de estudio autónomo. La historiografía pedagógica portuguesa ha privilegiado el estudio de la Educación Nueva y las reformas escolares europeas de las tres primeras décadas del Siglo XX, esto es el período que va del declinar de la monarquía a los inicios de la dictadura. ${ }^{36}$ Es cierto que el ideal de la escuela democrática contribuyó decisivamente a las concepciones de la educación moral y cívica de los renovadores europeos de la Escuela Nueva, llegando también a Portugal donde fue difundido por la generación de pedagogos portugueses que representaron a la Educación Nueva en el país: Adolfo Lima (1874-1943), António Faria de Vasconcelos (1880-1939), Álvaro Vieira de Lemos (1881-1972) y António Sérgio (1883-1969).

En realidad, los intentos de analizar la recepción del pensamiento y la obra de Dewey por los intelectuales y pedagogos portugueses han sido escasas ${ }^{37}$ y señalan un largo camino de investigación que todavía está por ser recorrido. Empero, como bien demostró Maria João Mogarro, no se puede considerar que, terminada la Escuela Nueva, haya habido un vacio pedagógico de cuatro décadas coincidente con la dictadura salazarista. Los autores que se reclamaron de la Educación Nueva y de la Escuela Activa no fueron sólo los que se opusieron al régimen y fueron por ello perseguidos. En una publicación reciente, ${ }^{38}$ demostró que el ideario de la Educación Nueva resistió a la pedagogía conservadora instituida a partir de los años 30 en Portugal y que varios textos pedagógicos producidos por profesores y utilizados en las instituciones de formación se referían claramente a sus principios en la argumentación pedagógica. Al revisar las obras de las bibliotecas personales de estos docentes y autores y de manuales de formación de profesores, la autora registró la presencia de un número significativo 
de obras extranjeras, principalmente de autores o traducciones de editoriales brasileños. Este descubrimiento asumió un significado particular, ya que, entre estos textos se encontraban las obras de John Dewey, subrayadas y comentadas por los respectivos propietarios. La autora escribe a propósito que "esta presencia revela la producción de un pensamiento pedagógico en la lusofonía, la circulación de saberes pedagógicos por los materiales impresos y las modalidades de apropiación que posibilitaron esa producción, estableciendo simultáneamente una red de comunicación entre las comunidades brasileña y portuguesa en el campo de la pedagogía, en particular entre los que tenían como referencia la Educación Nueva." 39

Basándose en el análisis de un conjunto de informes elaborados por becarios portugueses, Joaquim Pintassilgo mostró igualmente que en las tres primeras décadas del Siglo XX varios profesores pudieron entrar en contacto instituciones de enseñanza consideradas modelo en Suiza, Alemania, Francia, Bélgica e Inglaterra. ${ }^{40}$ Más allá de la riqueza de los relatos que señalaban las innovaciones pedagógicas, los métodos y la organización de las instituciones de enseñanza con que los pensionados se iban encontrando, estos incluían referencias a los autores y las obras a las que en Portugal no tenían acceso, en concreto a las de Dewey. Los viajes y visitas al extranjero representaron por eso mismo otro eje de las redes de comunicación entre las diversas comunidades discursivas, en particular en la difusión de obras de autores pedagógicos del otro lado del Atlántico que se entrecruzaban con el campo de producción del movimiento de la Escuela Nueva europea. Todos estos trabajos han desvelado la complejidad de los modos de apropiación, mecanismos de traducción y estrategias pedagógicas asociadas a la recepción de pensamiento de John Dewey en contextos culturales y sociales muy diversos. Thomas Popkewitz (2005) ha propuesto, por eso mismo, una lectura del pragmatismo en términos culturales, argumentando que, más allá de un conjunto de soluciones y de planos para la acción educacional, el pragmatismo encarna una tesis cultural que presenta una racionalidad, un conjunto articulado de condiciones de posibilidad, tanto para el cambio social como para la invención del self moderno.

\section{Notas finales}

Llegados a este punto, parecen evidentes las ventajas de proyectos de investigación histórico-comparados para la identificación de redes internas e internacionales de circulación de discursos pedagógicos, en particular en el campo de los grandes espacios culturales donde se comparten simultáneamente historias e identidades. Empero, como afirmó Nóvoa, la cuestión histórica y lingüística del universo lusófono no se ofrece al escrutinio del investigador como una configuración incontestable, sino como un campo en que subsisten, "por adhesión, o por rechazo," una historia común e identidades compartidas. ${ }^{41}$

Para el futuro, la tarea implica profundizar en el problema cruzando fuentes y referencias bibliográficas; el inventario de la literatura sobre el tema, incluyendo tesis de maestría y doctorado; identificar el corpus documental disperso en los archivos de los dos países; construir periodizaciones, ritmos y formas de apropiación e interpretación 
de los textos, traducciones y ediciones. Hay todavía todo un trabajo de censado, interpretación y análisis de contenido sobre la presencia de Dewey en las publicaciones en educación. Esa tarea, que se tornó factible a partir de la publicación del repertorio analítico A Imprensa de Educação e Ensino ${ }^{42}$ es, ciertamente, un recurso de investigación indispensable para toda la comunidad de historiadores de la educación de lengua portuguesa. Será también necesario censar el conjunto de las obras de Dewey traducidas al portugués y editadas en Brasil que circularon durante la primera mitad del Siglo XX en Portugal. Además, se precisa, todavía, estudiar las referencias a Dewey y al pragmatismo en los manuales de enseñanza y de formación de profesores, cartografiar los viajes al extranjero que importaron percepciones de realidades diferentes e identificar las selecciones y filtros a que esos discursos educativos y pedagógicos se sujetaron. Así, los problemas empíricos que se señalaron a lo largo del presente texto respecto a la renovación de los abordajes comparados en Historia de la educación entre Portugal, África y Brasil en la última década, sugieren un conjunto distinto de

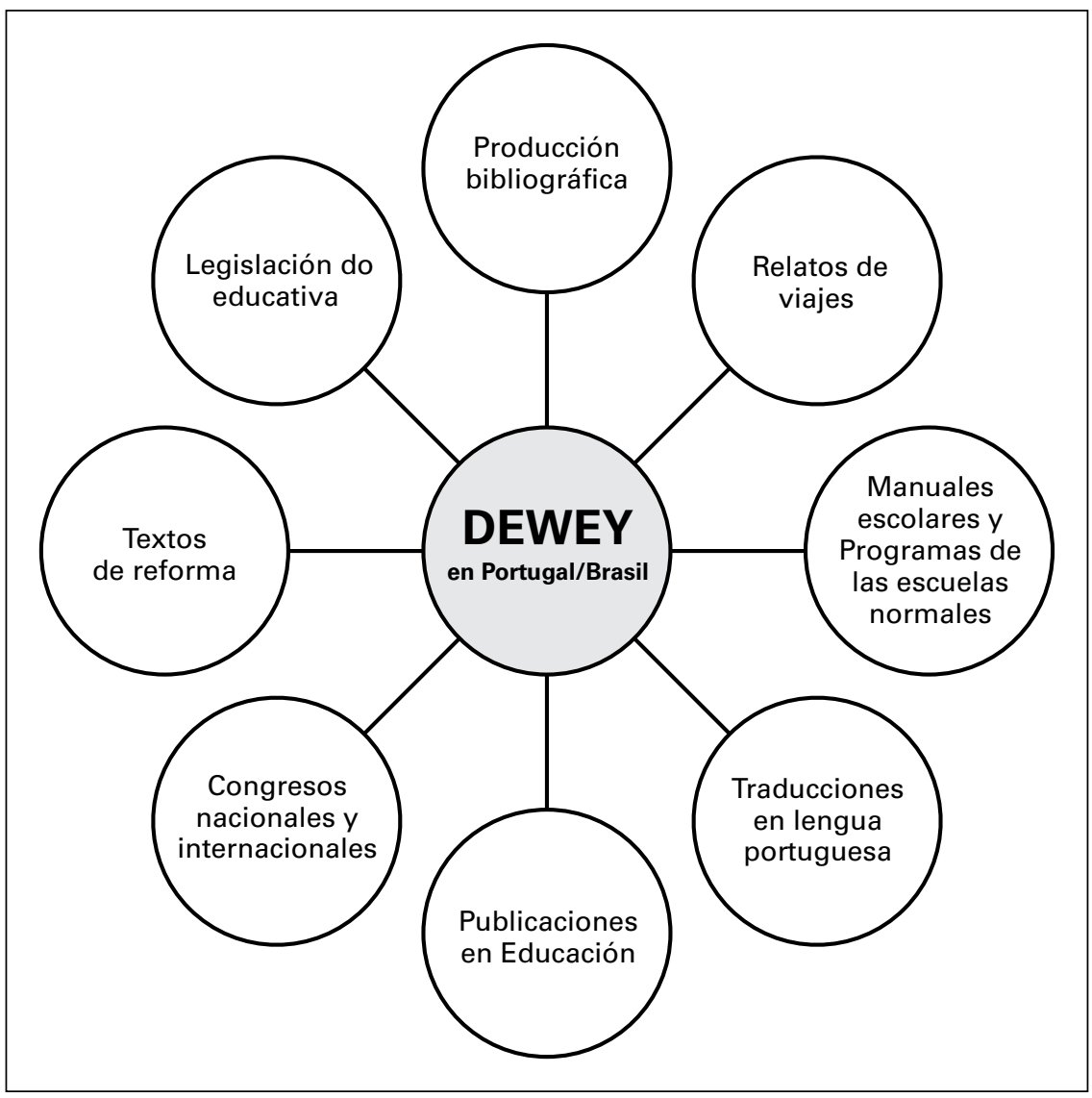

Figura 2: Redes de difusión-recepción de discurso educativo Brasil-Portugal|43 
ejes de desarrollo de la investigación comparada. La opción por una delimitación temporal amplia (1920-1950/60) tiene por objeto captar el proceso de construcción de la escuela de masas en los dos países, con sus ritmos y convulsiones políticas propias, aunque el período nuclear se situe entre la última década de Siglo XIX y las primeras décadas del Siglo XX. Esta periodización tiene la ventaja de delimitar el campo educativo con una configuración autónoma relacionada (más no subordinada) a los cortes políticos y las geografías nacionales. En suma, hay todavía mucho que explorar respecto a los modelos culturales que circularon entre Portugal y Brasil (y en el África donde el portugués es lengua oficial) para identificar los mecanismos de difusión, circulación y recepción que permitieron construir los argumentos educativos basados en la externalización hacia las situaciones mundiales. Los ocho ejes de investigación que se presentan a continuación tienen como objetivo delimitar, basándose en la investigación ya realizada, algunos de esos temas y problemas de investigación para el espacio luso-brasileño. Espero que las sugestiones presentadas estimulen el desarrollo de proyectos de investigación comparados y contribuyan a identificar el campo de las comunicaciones educativas entre Portugal, África y Brasil, en particular el lugar de John Dewey en la producción de un conocimiento educativo especializado.

\section{Bibliografia}

Luis M. Carvalho, Nós através da Escrita: Revistas, Especialistas e Conhecimento Pedagógico (1920-1936) Cadernos Prestige (3) (Lisboa: Educa, 2000).

Marta C. Carvalho, "O debate sobre a identidade da cultura brasileira nos anos 20: O americanismo de Anísio," in A. L. Smolka and M. C. Menezes, orgs. Anisio Teixeira, 1990-2000. Provocações em Educação (Campinas, SP: Autores Associados/Bragança Paulista, SP: Universidade de S. Francisco, 2000).

Roger Chartier, A História Cultural, entre práticas e representaçōes (Lisboa: Difel, 1990).

António C. Correia y Vera Gaspar da Silva, A Lei da Escola: Os sentidos da Construção da Escolaridade Popular Através dos Textos Legislativos em Portugal e Santa Catarina-Brasil (1880-1920). Cadernos Prestige (16). (Lisboa: Educa, 2003).

John Dewey, "How We Think," in Essays on Education and Politics, 1916. The Middle Works of John Dewey, 1899-1924, vol. 6, 1910-11: Essays and How We Think, ed. Jo Ann Boydston (Carbondale \& Edwardsville: Southern Illinois University Press, 1985).

John Dewey, "Democracy and Education," en The Middle Works of John Dewey, 1899-1924, vol. 9, 1916: Democracy and Education, ed. Jo Ann Boydston (Carbondale \& Edwardsville: Southern Illinois University Press, 1985).

John Dewey, A Escola e a Sociedade e A Criança e o Curriculo (Lisboa: Relógio d’Água, 2002) [1900 y 1902].

Ana Isabel Madeira, "Portuguese, French and British Discourses on Colonial Education: Church-State Relations, School Expansion and Missionary Competition in Africa, 1890-1930," Paedagogica Historica 41, n. 1/2 (2005): 31-60.

E.G. Malherbe, J.J.G. Carson, I. Jones, y D. Rheinallt eds., Educational Adaptations in a Changing Society. Report of the South African Education Conference held in Capetown and Johannesburg in July, 1934, under the auspices of The New Education Fellowship (Capetown \& Johannesburg: Juta and Co., 1937). 
António Nóvoa y Júlio Ruiz Berrio eds. A História da Educação em Espanha e Portugal: Investigações e Actividades (Lisboa: Sociedade Portuguesa de Ciências da Educação, 1993).

António Nóvoa y Thomas S. Popkewitz eds., Reformas Educativas e Formação de Professores (Lisboa: Educa, 1992).

António Nóvoa y Tali Yariv-Mashal, "Comparative Research in Education: a mode of governance or a historical journey?," Comparative Education 39, n. 4 (2003): 423-38.

António Nóvoa, Le Temps des Professeurs. Analyse Sócio-Historique de la Profession Enseignante au Portugal (XVIII-XX siècle) vol.1 (Lisboa: Instituto Nacional de Investigação Científica, 1987).

António Nóvoa, "États des lieux de L’Éducation comparée, paradigmes, avancées et impasses, " in Autour du Comparatisme en Éducation, org. Régine Sirota (Paris: Presses Universitaires de France, 2001), 41-68.

António Nóvoa, Luis M. Carvalho, António C. Correia, Ana I. Madeira, y Jorge do Ó, "Flows of Educational Knowledge: The Space-Time of Portuguese-Speaking Countries," en Internationalisation, Comparing Educational Systems and Semantics, ed. Marcelo Caruso (Frankfurt am Main/Berlin/Bern/New York/Oxford/Wien: Peter Lang, 2002).

António Nóvoa, Luis M. Carvalho, António C. Correia, Ana I. Madeira, y Jorge do Ó, Educational Knowledge and its Circulation: Historical and Comparative Approaches of Portuguese-Speaking Countries. Cadernos Prestige, Final series (5/7) (Lisboa: Educa, 2003).

António Nóvoa, Marc Depaepe, Erwin V. Johanningmeier, y Diana S. Arango eds., Para uma História da Educação Colonial/Hacia una Historia de la Educación Colonial (Porto: Sociedade Portuguesa de Ciências da Educação y Educa, 1966).

Thomas S. Popkewitz, "National Imaginaries, the Indigenous Foreigner, and Power: Comparative Educational Research," in Discourse Formation in Comparative Education, ed. J. Schriewer (Frankfurt am Main: Peter Lang, 2003), 261-94.

T. Popkewitz, Struggling for the Soul. The Politics of Schooling and the Construction of the Teacher (New York and London: Teachers College/Columbia University, 1998), 30-31.

Jürgen Schriewer, "World-System and Interrelationship Networks: The Internationalization of Education and the Role of Comparative Inquiry," in Educational Knowledge:

Changing relationships between the state, civil society, and the educational community, ed. T. Popkewitz (New York: SUNY Press, 2000), 305-43.

Jürgen Schriewer, Formas de Externalização no Conhecimento Educacional. Cadernos Prestige (5) (Lisboa: Educa, 2001).

Jürgen Schriewer, "Comparative Education Methodology in Transition: Towards a Science of Complexity?," en Discourse Formation in Comparative Education, ed. J. Schriewer (Frankfurt am Main: Peter Lang, 2003), 3-52.

Jürgen Schriewer, «Les Mondes Multiples de l'Éducation: Rhétoriques Educatives Mondialisées et Cadres Socio-Culturels de la Réflexion, " en Identity, Education and Citizenship-Multiple Interrelations, eds. Jonas Sprogøe and Thyge Winther-Jensen (Frankfurt am Main/Berlin/ Bern/Bruxelles/New York/Oxford/Wien: Peter Lang, 2006), 139-63.

Jürgen Schriewer y Edwin Keiner, "Communication Patterns and Intellectual traditions in Educational Sciences: France and Germany," Comparative Education Review 36, n. 1 (1992): 25-51.

Vivian B. Silva and António C. Correia, "Saberes em viagem nos manuais pedagógicos (Portugal-Brasil)," Cadernos de Pesquisa 34, no. 123 (2004): 613-32.

V.B. Silva, História das leituras para professores: um estudo da produção e circulação de saberes especializados nos "manuais pedagógicos" brasileiros (1930-1971) (São Paulo: Dissert. (Mest.) Feusp., 2001). 


\section{Notas}

1. António Nóvoa, "Tempos da Escola no espaço Portugal-Brasil-Moçambique: dez digressões sobre um programa de investigação," en A Difusão Mundial da Escola, eds. A.Nóvoa y J. Schriewer (Lisboa: Educa, 2000), 127.

2. A. Nóvoa y Jürgen Schriewer, eds., A difusão mundial da escola: Alunos, Professores, Currículo, Pedagogia (Lisboa: Educa, 2000).

3. Jeffrey Mirel, Old Educational Ideas, New American Schools: Progressivism and the Rhetoric of Educational Revolution. Paedagogica Historica, 39, no. 4 (Agosto, 2003): 478-79.

4. John Dewey se refirió varias veces a Francis W. Parker como el "padre de la educación progresista” y, así, escogió la escuela que Parker había fundado en Quincy, en Massachusetts, para enviar sus niños. En 1875, Parker fundó una escuela en Chicago considerada un modelo de educación y de formación de profesorado de acuerdo con los principios progresivos. Francis Parker fue autor de la obra Talks on Pedagogy (1894) probablemente el primer tratado de pedagogía que alcanzó divulgación internacional, en el cual expone sus innovadores métodos de enseñanza: situar los niños en centro de proceso educativo, relacionar las materias escolares para reforzar el significado de sus contenidos para los alumnos y reorganizar las escuelas para transformarlas en comunidades democráticas embrionarias (Campbell, 1968).

5. John Dewey, "Schools of To-morrow," en The Middle Works of John Dewey, 1899-1924, ed. Jo Ann Boydston, vol. 8, 1915: Essays, German Philosophy and Politics, and Schools of To-Morrow. (Carbondale y Edwardsville: Southern Illinois University Press, 1985), 391.

6. A. Nóvoa, "A República e a Escola: das Intenções generosas ao desengano das realidades," Revista Portuguesa de Educação 1, no. 3 (1988): 75.

7. A través de la acción del Instituto de Ciencias de la Educación - Jean Jacques Rousseau (IJJR) (1912); del Centro Internacional de las Escuelas Nuevas (BIEN) (1899), de la Liga Internacional para la Educación Nueva (LIEN) (1921) y de los periódicos Pour l'Ėre Nouvelle, dirigido por Adolphe Ferrière. Los ideales de la educación progresiva se divulgaron también a través de la New Education Fellowship (NEF) (1921) cuya fundadora, Beatrice Ensor, dirigía también la revista The New Era (en Inglaterra). La International Review of Misions y la revista Africa: the Journal of the Royal African Society desempenaron un papel importante en la divulgación de los métodos de educación americanos en las colonias africanas pero sin referencias explícitas a Dewey. Lo opuesto sucedió con la Overseas Education, una publicación británica editada por el Advisory Committee on Education in the Colonies bajo la responsabilidad de Arthur Mayhew (1929-1946) y posteriormente Frank Ward (1946-1963).

8. En especial la revista Progressive Education (USA).

9. La influencia de Dewey en el mundo de la educación se documenta en un conjunto de artículos que se citan a continuación, en su mayoría son estudios de casos nacionales. A título informativo se citan las contribuciones, por orden de publicación, lo que permite cartografiar las peregrinaciones de Dewey por el mundo, lo que facilita futuras investigaciones sobre el tema: I. L. Kandel, "The Influence of Dewey Abroad," Teachers College Record 31, n. 3 (1929): 239-44; William W. Brickman, "John Dewey's Foreign Reputation as an Educator," School and Society, 70 (1949): 257-65; W.W. Brickman y Stanley Lehrer eds., John Dewey Master Educator (New York: John Wiley, 1975); A. Roberto Munizaga "John Dewey, filósofo de América," en Ediciones de los Anales de la Universidad de Chile (1960), 9; Ronald Kronish, "John Dewey's Influence on Jewish Educators: The Case of Alexander M. Dushkin," Teachers College Record 83, n. 3 (1982): 419-33; A. Harry Pasow, "John Dewey's influence on education around the world," Teachers College Record 83, n. 3 (1982): 401-18; 
W.W. Brickman, “The Turkish cultural and educational revolution: John Dewey's Report of 1924," Western European Education 16, n. 5 (1984): 3-18; Ronald K. Goodenow, "The Progressive Educator and the Third World: a First Look at John Dewey," History of Education 19, n. 1 (1990): 23-40; Naoko Saito, "Education for Global Understanding: Learning From Dewey's Visit to Japan," Teachers College Record 105, n. 9 (2003): 1758-73; Thomas S. Popkewitz ed., Inventing the Modern Self and John Dewey: Modernities and the Traveling of Pragmatism in Education (New York: Palgrave Macmillan, 2005).

10. Popkewitz, Inventing the Modern Self and John Dewey, 10-11.

11. Ana Isabel Madeira, Ler, Escrever e Orar: Uma análise histórica e comparada dos discursos sobre a educação, o ensino e a escola em Moçambique, 1850-1950. Tese de Doutoramento em Ciências da Educação (Educação Comparada). Faculdade de Psicologia e de Ciências da Educação da Universidade de Lisboa (2007).

12. Ibid., 327-33.

13. Popkewitz, Inventing the Modern Self and John Dewey, 8.

14. Robert Goodenow (1990) refiere la influencia de Dewey en las reformas de Nigeria, sin citar o especificar ninguna referencia bibliográfica.

15. A.I. Madeira, "Framing Concepts in Colonial Education: A Comparative Analysis of Educational Discourses at the Turn of the Nineteenth to the Twentieth Century," en Identity, Education and Citizenship_Multiple Interrelations, eds. Jonas Sprogøe and Thyge Winther-Jensen (Frankfurt am Main/Berlin/Bern/Bruxelles/New York/Oxford/Wien: Peter Lang, 2006), 225-38.

16. Omer Buyse, Méthodes Américaines d'Education Générale et Technique, 2nd ed. (Presses de L'Établissement Litographique de Charleroi,1909); O. Buyse, Métodos americanos de educação geral e técnica (trad. especial para a revista de Estudos Pedagógicos por Luiz Ribeiro de Senna) (Bahia: Imprensa Oficial do Estado, 1927); Madeira, Ler, Escrever e Orar, 276-91.

17. Madeira, Ler, Escrever e Orar, 307-27; A.I. Madeira, "Comparing Colonial Education Discourses in the French and Portuguese African Empires: An Essay on Hybridization," en International Handbook of Comparative Education, eds. Robert Cowen y A. M. Kazamias, (London \& New York: Springer, 2009), 165-78.

18. Isaac L. Kandel, “The Influence of Dewey Abroad.” Teachers College Record 31, no. 3 (1929): 240.

19. Lawrence Cremin, "What Happened to Progressive Education?," Teachers College Record 61, n. 1 (1959): 23-29. http://www.tcrecord.org [Accessed on June 20, 2006].

20. Daniel Tröhler, "The "Kingdom of God on Earth" and Early Chicago Pragmatism," Educational Theory 56 n. 1 (2006): 98.

21. Madeira, Ler, Escrever e Orar, 324-33.

22. O. Buyse, Méthodes Américaines d'Éducation Générale et Technique (Charleroi: Dunot et E. Pinat, 1908), 581-91.

23. Madeira, Ler, Escrever e Orar, 327.

24. Luís M. Carvalho y Jaime Cordeiro, "Brasil-Portugal nos circuitos do discurso pedagógico especializado (1920-1935),” Cadernos Prestige 9 (Lisboa: Educa, 2002).

25. Ibid.

26. António C. Correia y Vivian B. Silva, "Manuais Pedagógicos - Portugal e Brasil, 1930 a 1971 - Produção e Circulação Internacional de Saberes Pedagógicos," Cadernos Prestige 13 (Lisboa: Educa, 2002). 
27. A.C. Correia y Rita de Cassia Gallego, "Escolas Públicas Primárias em Portugal e em S. Paulo: Olhares sobre a organização do tempo escolar (1880-1920)," Cadernos Prestige 21 (Lisboa: Educa, 2004).

28. Correia y Silva, "Manuais Pedagógicos — Portugal e Brasil."

29. V.B. Silva, "Saberes em viagem nos manuais pedagógicos: construções da escola em Portugal e no Brasil (1870-1970)," Revista Brasileira de Educação 12, n. 35 (2007): 268-76.

30. Silva, "Saberes em viagem nos manuais pedagógicos," 235.

31. J. Schriewer, "Sistema Mundial e inter-relacionamento de redes: A internacionalização da educação e o papel da pesquisa comparativa," Revista Brasileira de Estudos Pedagógicos 76, n. 182/183 (1995): 241-304; J. Schriewer, "World-System and Interrelationship Networks: The Internationalization of Education and the Role of Comparative Inquiry," en ed. Thomas Popkewitz, Educational Knowledge: Changing relationships between the state, civil society, and the educational community (New York: SUNY Press, 2000), 305-43; J. Schriewer, "Estados-modelos e sociedades de referência: externalização em processos de modernização," en A Difusão Mundial da Escola, eds. A. Nóvoa and J. Schriewer (Lisboa: Educa, 2000).

32. Carvalho y Cordeiro, "Brasil-Portugal nos circuitos do discurso pedagógico," 51.

33. Luis M. Carvalho, Nós através da Escrita: Revistas, Especialistoas e Conhecimento Pedagógico (1920-1936). Cadernos Prestige (3) (Lisboa: Educa, 2000); Carvalho and Cordeiro, "Brasil — Portugal nos circuitos do discurso pedagógico."

34. A. C. Correia y V.B. Silva, Manuais Pedagógicos - Portugal e Brasil, 1930 a 1971 - Produção e Circulação Internacional de Saberes Pedagógicos. Cadernos Prestige (13) (Lisboa: Educa, 2002); A. C. Correia y Vera Gaspar da Silva, A Lei da Escola: Os sentidos da Construção da Escolaridade Popular Através dos Textos Legislativos em Portugal e Santa Catarina - Brasil (1880-1920) Cadernos Prestige (16) (Lisboa: Educa, 2003); Correia y Gallego, "Escolas Públicas Primárias em Portugal e em S. Paulo."

35. Ana Waleska Mendonça, Universidade e formação de professores: Uma perspectiva integradora. A "Universidade de Educação" de Anísio Teixeira. Rio de Janeiro, Departamento de Educação, PUCRJ, Tese de Doutoramento (1993); A.W. Mendonça, Anísio Teixeira e a Universidade de Educação. Rio de Janeiro: EdUERJ (2002); Zaia Brandão y A.W. Mendonça, eds. Uma tradição esquecida: por que não lemos Anísio Teixeira? (Rio de Janeiro: Forma\& Acção, 2008 2nd ed.); A.W. Mendonça, L.N. Xavier, V.A. Breglia, M. Chaves, M.C. Oliveira, C. Lima, y P.B. Santos, "Pragmatismo e Desenvolvimentismo no pensamento educacional brasileiro dos anos de 1950/1960," Revista Brasileira de Educação 11, n. 31 (2006): 96-113; Marta C. Carvalho, "O debate sobre a identidade da cultura brasileira no anos 20: O americanismo de Anísio," en Provocações em Educação, orgs. A.L. Smolka y M.C. Menezes (Campinas, SP: Autores Associados/Bragança Paulista, SP: Universidade de S. Francisco, 2000); Diana G. Vidal, "Escola Nova e Processo Educativo," en 500 anos de Educação no Brasil,eds. Eliane Lopes, Filho L. Faria y Cynthia G. Veiga (Belo Horizonte: Autêntica, 2007, 3rd ed. 1 reimp.), 497-517; Clarice Nunes, "Anísio Teixeira entre nós: A defesa da educação como direito de todos," Educação e Sociedade XXI, n. 73 (2000): 9-40; C. Nunes, Anisio Teixeira: a poesia em acção (São Paulo: EDUSF,2000); C. Nunes, "(Des) Encantos da Modernidade Pedagógica," en 500 anos de Educação no Brasil, Lopes, et. al., 371-98; Léa Maria V. de Castro, Uma escola de professores: formação de docentes na Reforma Anísio Teixeira (1931-1935) (Rio de Janeiro, PUCRJ, Departamento de Educação, Dissert. Mestrado, 1986); M.V. Cunha, John Dewey: Uma filosofia para educadores em sala de aula (Petrópolis: Vozes, 1994); M.V. Cunha, A educação dos educadores: da Escola Nova à escola de Hoje (Campinas: Mercado de Letras, 1995); M.V. Cunha, "Dewey e Piaget no Brasil dos anos trinta," Cadernos de Pesquisa, São Paulo, n.97 (1996): 5-12; M.V. Cunha, "A presença 
de John Dewey na constituição do ideário educacional renovador," Educação em Revista, Belo Horizonte, n. 31 (1999): 77-91; M.V.Cunha, "Três versões do pragmatismo deweyano no Brasil dos anos 50," Educação e Pesquisa, SP, no. 2 (1999): 39-55; M.V. Cunha, "John Dewey: Filosofia, Política e Educação," Perspectiva, Florianópolis, 19, n. 2 (2001): 371-88; M.V. Cunha, "John Dewey e o pensamento educacional brasileiro: a centralidade da noção de movimiento," Revista Brasileira de Educação, Rio de Janeiro, n. 17 (2001): 86-99; J. A. De L. Rocha, ed. Anisio em movimento: a vida e as lutas de Anísio Teixeira pela escola pública e pela cultura do Brasil (Salvador: Fundação Anísio Teixeira, 1992).

36. A. Nóvoa, António, Le Temps des Professeurs. Analyse Sócio-Historique de la Profession Enseignante au Portugal (XVIII-XX siècle) Vol. I (Lisboa: Instituto Nacional de Investigação Científica, 1987); Nóvoa, "A República e a Escola"; A. Nóvoa, dir. A Imprensa de Edução e Ensino: Repertório Analitico (Séculos XIX-XX) (Lisboa: Instituto de Inovação Educacional, 1993); A. Nóvoa, "On History, History of Education, and History of Colonial Education," Paedagogica Historica, International Journal of the History of Education, Supplementary Series. Vol. I (1995): 23-61; A. Nóvoa, “'Educação Nacional' (1930-1974): Análise Histórica e Historiográfica," en Los Caminos Hacia la Modernidad Educativa en España e Portugal (1800-1975). Actas do II Encontro Ibérico de História de la Educación, Zamora, 1995 (1997); A. Nóvoa, « Modeles d'Analyse en Éducation Comparée : Le Champ et la Carte. In Histoire et Comparaison (Essais sur l'Education)" (Lisboa : Educa, 1998), 75 ; A. Nóvoa, dir. Dicionário de Educadores Portugueses, (Porto: Edições Asa, 2003); A. Nóvoa, "La Pédagogie, Les enseignants et la recherche, réflexions en chantier " Cadernos Prestige 19 (Lisboa: Educa, 2005); Joaquim Pintassilgo, República e formação de cidadãos. A educação cívica nas escolas primárias da $1^{\circ}$ República Portuguesa (Lisboa: Edições Colibri, 1998); Rogério Fernades, As ideias pedagógicas de Francisco Adolfo Coelho, (Lisboa: Instituto Gulbenkian de Ciência/ Centro de Investigação Pedagógica, 1973); R. Fernades, Os Caminhos do ABC. Sociedade Portuguesa e Ensino das Primeiras letras do Pombalismo a 1820, (Porto: Porto Editora, 1994); Áurea Adão, O Estatuto Sócio-profissional do Professor Primário em Portugal (1901-1951). (Oeiras: Instituto Gulbenkian de Ciência, 1984); Á. Adão, Estado Absoluto e Ensino das Primeiras Letras: As Escolas Régias (1772-1794). 2 vols. Lisboa: Faculdade de Ciências da Universidade de Lisboa, Departamento de Educação. Tese de Doutoramento, 1995; M. Filomena Mónica, Educação e Sociedade no Portugal de Salazar (Lisboa: Editorial Presença/ GIS, 1978); Rómulo de Carvalho, História do Ensino em Portugal desde a Fundação da Nacionalidade até ao fim do Regime de Salazar-Caetano (Lisboa: Fundação Calouste Gulbenkian, 1986); Justino Magalhães, Justino, Ler e Escrever no Mundo Rural do Antigo Regime. Um contributo para a História da Alfabetização e da Escolarização em Portuga. (Braga: Universidade do Minho/ Instituto de Educação, 1994).

37. Jorge Ramos do Ó, "Dewey on Lima or the social prosthesis in the Construction of the new Education discourse in Portugal (1925-1936)" en Inventing the Modern Self and John Dewey: Modernities and the Traveling of Pragmatism in Education, ed. T. Popkewitz (New York: Palgrave Macmillan, 2005), 111-31; Madeira, Ler, Escrever e Orar.

38. Maria João Mogarro, "Bibliotecas particulares e saberes pedagógicos: Circulação e apropriação de modelos culturais" in História da Escola em Portugal e no Brasil, eds. J. Pintassilgo, M. Freitas, M.J. Mogarro, y M.C. Carvalho (Lisboa: Edições Colibri/Centro de Investigação em Educação, Faculdade de Ciências da Universidade de Lisboa, 2006), 233-57.

39. Ibid., 244, XXXX.

40. J. Pintassilgo, Images and Interpretations of New Education in Portugal. The Reports of Portuguese Teachers holders visiting European educational institutions. Comunicação apresentada à International Standing Conference for the History of Education - ISCHE 26 - realizada entre 14 e 17 de Julho de 2004 na Universidade de Genève (Suíça) [policopiado]. 
41. Nóvoa, "Tempos da Escola no espaço Portugal-Brasil-Moçambique," 127.

42. Nóvoa, A Impresa de Edução e Ensino.

43. Leyenda: (1) Inventario critico de la producción bibliográfica portuguesa y brasileña sobre la obra de John Dewey (fuentes primarias y secundarias); (2) el pragmatismo de Dewey a través de los relatos de viaje de los pedagogos portugueses; (3) Dewey en los manuales de formación de los normalistas y programas de formación de profesores de magisterio primario (1910-1930); (4) las traducciones de la obra de Dewey y la su circulación en las bibliotecas públicas y en las colecciones privadas portuguesas y brasileñas (1910-1950/60); (5) la contribución de las publicaciones en educación y enseñanza para la circulación de conocimiento pedagógico PortugalBrasil (1910-1950); (6) la participación luso-brasileira en Congresos internacionales y la representación en organismos internacionales y (7) el discurso educativo de la modernización a través de los textos de reforma y (8) de la legislación sobre el enseñanza. 